\title{
Chronic Distal Radioulnar Joint Dislocation: A Case Report
}

\section{Luxacion Cronica de la Articulacion Radiocubital Distal: Relato de un Caso}

\author{
Leonor Fernandes $^{1}$ João Sousa ${ }^{1}$ Fernando Cruz $^{2}$ \\ ${ }^{1}$ Centro Hospitalar do Oeste, Caldas da Rainha, Portugal \\ 2 Hospital dos Lusíadas, Lisboa, Portugal \\ Address for correspondence Leonor Fernandes, MD, Centro \\ Hospitalar do Oeste - Unidade de Torres Vedras, Rua Dr. Aurélio \\ Rev Iberam Cir Mano 2019;47:137-140. \\ Ricardo Belo 2560 - 324 Torres Vedras, Portugal \\ (e-mail: leonorf.md@gmail.com).
}

Abstract
Keywords
- chronic
- dislocation
- distal radioulnar joint
- wrist

Resumen

Palabras clave

- luxacion

- cronica

- articulacion radiocubital distal

- muñeca
Dislocation of the distal radioulnar joint (DRUJ) usually occurs associated with a distal radius fracture. An isolated dislocation, without a radius fracture, is a rare situation. We present a case of neglected isolated DRUJ dislocation in a 30-year-old manual laborer. The treatment was performed 4 months after the initial injury. Open reduction and fixation were performed. This resulted in a stable, pain-free joint, and the patient resumed his previous work.

Surgical techniques of foveal reattachment and dorsal capsuloplasty have been described for chronic DRUJ instability. An isolated and dislocated DRUJ is an uncommon injury that may be misdiagnosed and initially mistreated. There haven't been many reports in the literature of a case such as this.

La luxacion de la articulación radiocubital distal sucede generalmente asociada con una fractura del radio distal. Una luxación aislada, sin fractura del radio, es una situación rara.

Presentamos un caso de una luxación aislada non diagnosticada en un trabajador manual. El tratamiento se realizó 4 meses después de la lesión inicial. Reducción abierta e fijación fueron realizados. Esto resulto en una articulación estable, sin dolor e lo paciente ha regresado a su trabajo previo.

Las técnicas quirúrgicas de fijación en la fóvea e capsuloplastia dorsal fueran descritas para la instabilidad de la articulación radiocubital distal. Una luxación aislada de la articulación radiocubital distal es una lesión infrecuente e puede ser mal diagnosticada e mal tratada inicialmente. No hay muchos casos como este publicados en la literatura.

\section{Introduction}

The distal radioulnar joint (DRUJ) is an articulation located between the sigmoid notch of the radius and the ulnar head. Because these articular surfaces have different radii of curvature, the soft tissues are important stabilizers of the joint. ${ }^{1}$ The main soft tissues stabilizing structures are the triangular fibrocartilage complex (TFCC), the pronator quadratus, and the interosseous membrane. ${ }^{2}$

A DRUJ dislocation is a rare entity. It is usually associated with a distal radius fracture, and a DRUJ dislocation without a radius fracture is an even rarer injury. This injury, if misdiagnosed or mistreated, results in a complete loss of pronation-supination, which entails a great functional limitation. received

October 14, 2018

accepted

August 5, 2019
DOI https://doi.org/

10.1055/s-0039-1698789. ISSN 1698-8396.
Copyright $\odot 2019$ Thieme Revinter

Publicações Ltda, Rio de Janeiro, Brazil
License terms

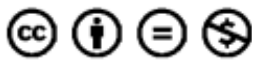


The purpose of the present report is to describe a rare clinical case and to discuss the treatment that was chosen for it.

\section{Clinical Case}

A 30-year-old manual laborer fell on his outstretched hand. On the first evaluation at the emergency room department, a complete dislocation of the DRUJ associated with a fracture of the ulnar styloid was diagnosed (-Figs.1, 2 and 3). A closed reduction and immobilization with a cast and splint for three weeks were attempted. After the removal of the splint, he was sent to rehabilitation. After several weeks, the patient complained of pain and low range of movement. At this point, he was referred to us.

At our first evaluation, 4 months after the initial injury, the patient was found to have no supination and $10^{\circ}$ of pronation. He had ulnar wrist pain. The flexion and extension of the injured wrist were similar to that of the other wrist. X-rays and a computed tomography (CT) scan confirmed a complete volar dislocation of the DRUJ and a non-united fracture of the ulnar styloid (-Fig. 4). We concluded that either the initial closed reduction was not effective, or that the joint re-dislocated while still immobilized in the splint.

A closed reduction was attempted with no success. Surgical treatment was performed. A dorsal approach through the 5th compartment was performed, as described by Garcia-Elias et al. $^{3}$ An open reduction of the dislocation was performed (-Fig. 5). The ulnar styloid fracture reduced spontaneously after the reduction of the DRUJ. After the reduction, the

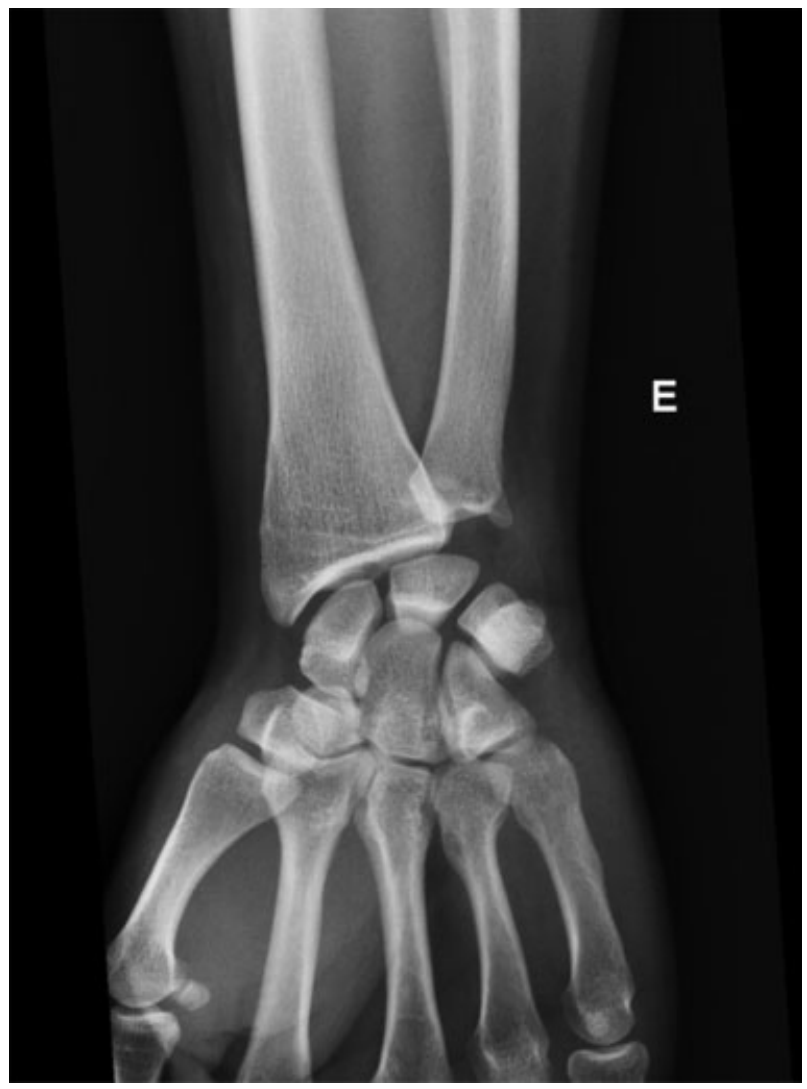

Fig. 1 Initial X-ray - AP View.

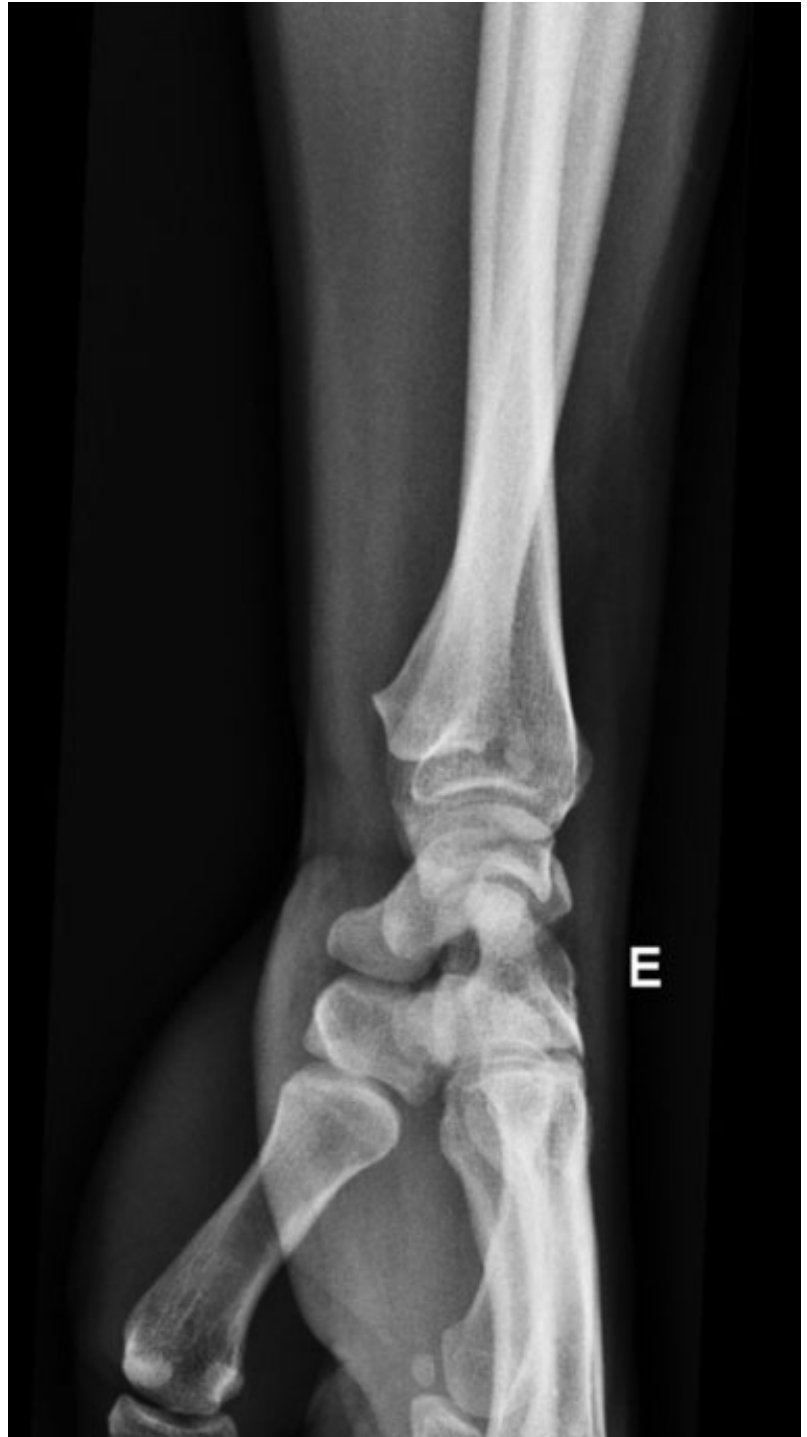

Fig. 2 Initial X-ray - Lateral View.

pronation was found to be complete and stable, but every attempt at supination resulted in a new volar dislocation of the ulnar head. The TFCC had ruptured from the fovea, and was fixed to it with a bone anchor. The dorsal capsule was closed and reinforced with a plicature. The DRUJ was temporarily fixed with two Kirschner wires in neutral position. The patient was immobilized with a cast and splint below the elbow. After two weeks, the sutures were removed, and full flexion and extension of the wrist and elbow were allowed. A block of the pronation and supination was maintained until 7 weeks after surgery, when the Kirschner wires were removed. Then the patient was allowed to perform full pronation, but used a dynamic splint that would block supination. Then, he initiated the rehabilitation. Twelve weeks after surgery, total range of movement was allowed.

Six months after surgery, the patient had full pronation and $20^{\circ}$ of supination. His wrist was stable, pain-free, and had the same strength as his uninjured side ( $\mathbf{F i g}$. 6). The X-rays showed a healed ulnar styloid and a reduced DRUJ ( - Fig. 7 ). He resumed his previous occupation without limitations. 


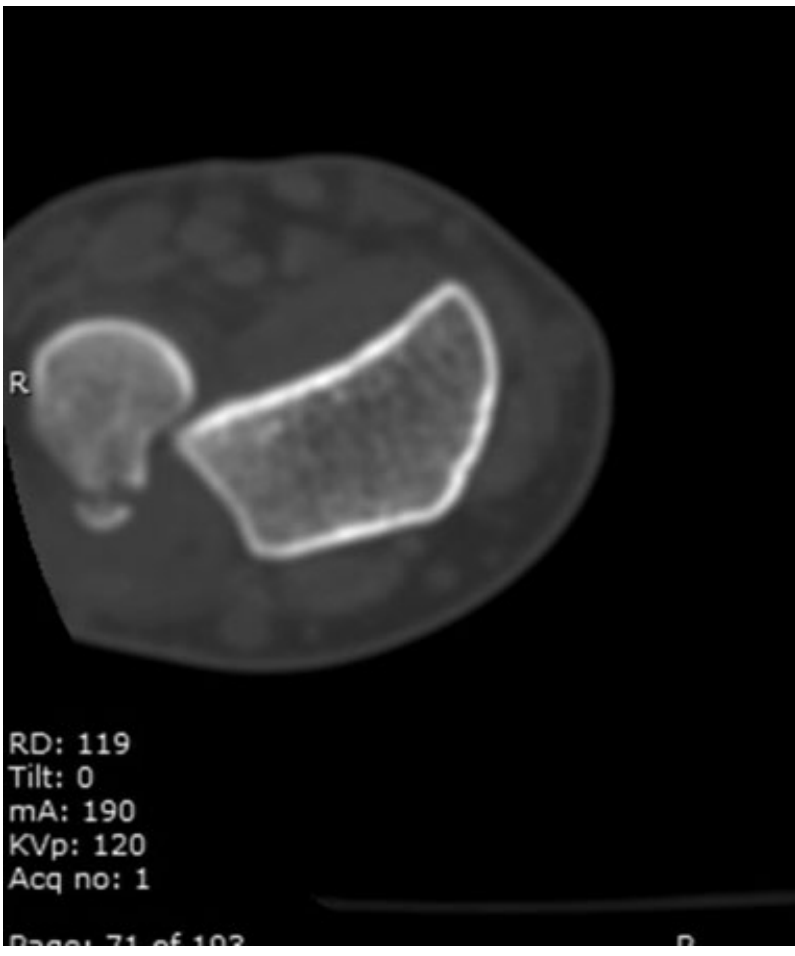

Fig. 3 Initial CT Scan.

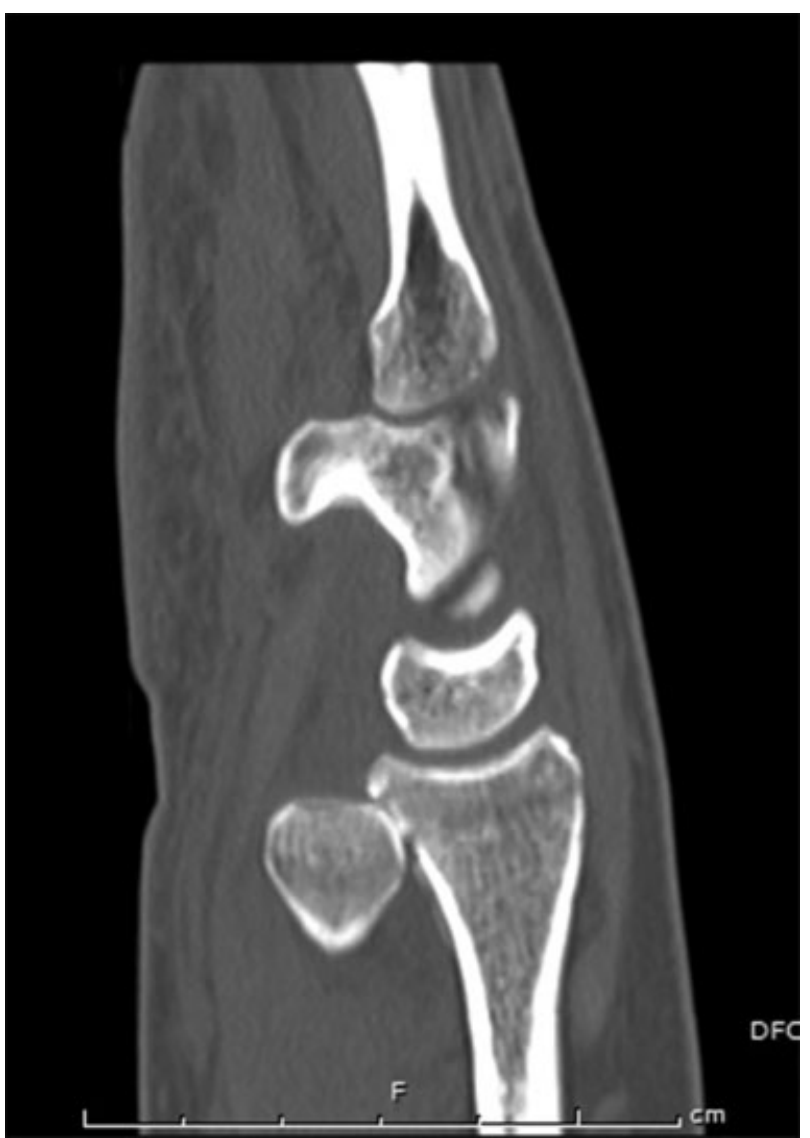

Fig. 4 CT Scan at 4 months.

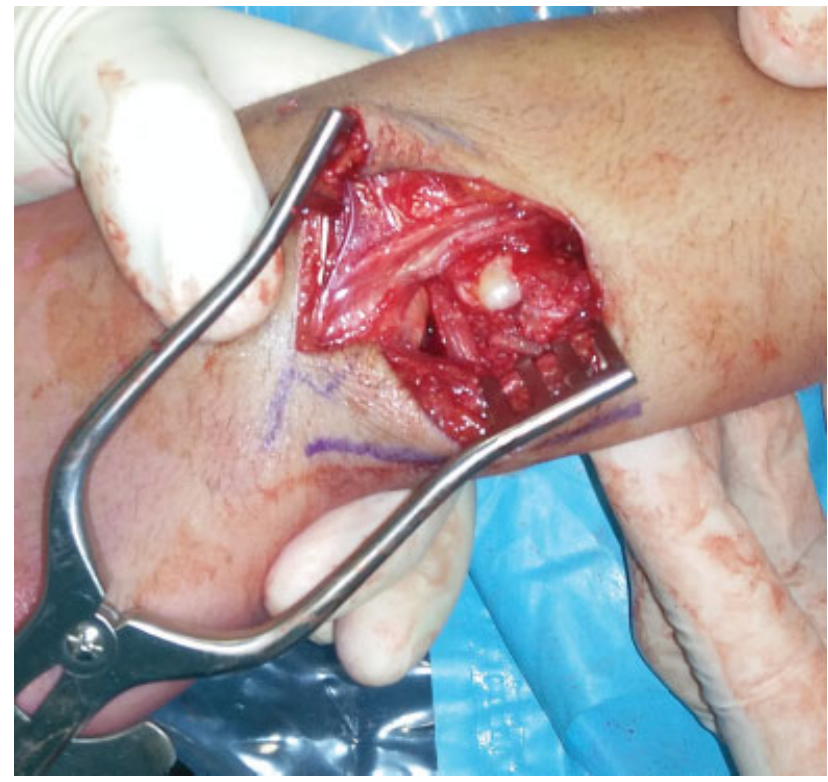

Fig. 5 Dorsal approach to the DRUJ.

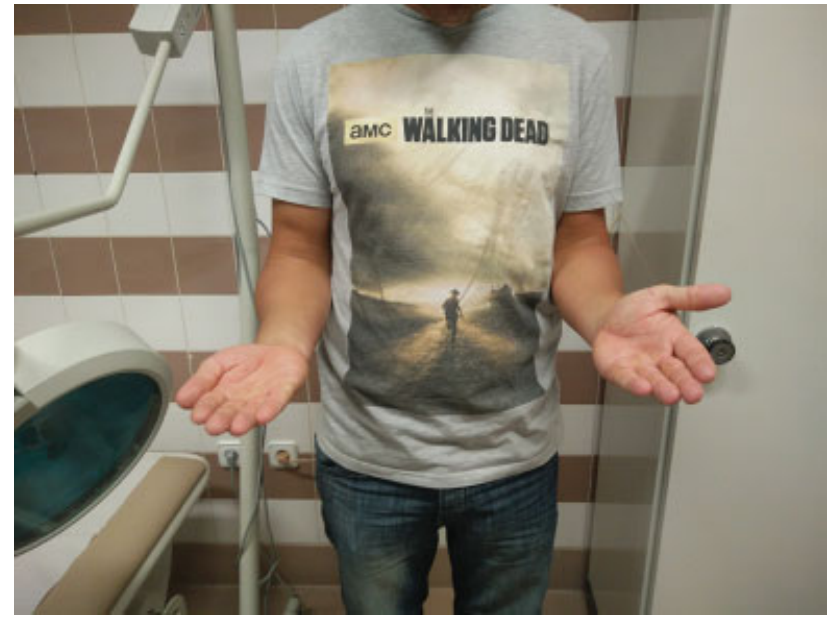

Fig. 6 Final clinical result.

\section{Discussion}

A DRUJ dislocation without an associated radius fracture is a rare injury. Some reports state that a dorsal dislocation is more common than a volar dislocation. ${ }^{2}$ Most articles on this subject refer to cases diagnosed and treated in the acute setting. This makes the case herein reported even less common.

Garrigues and Aldridge ${ }^{4}$ described a case of volar DRUJ dislocation treated in the acute stage in which no ulnar styloid fracture occurred. Closed reduction was not possible, and open reduction was necessary. Ellanti and Grieve ${ }^{5}$ also described a case of volar acute DRUJ dislocation in which an open reduction with TFCC reattachment was also necessary. Rijal et al $^{6}$ described a volar DRUJ dislocation treated in the acute setting with closed reduction and percutaneous fixation. Acar $^{7}$ presented three cases of isolated DRUJ 


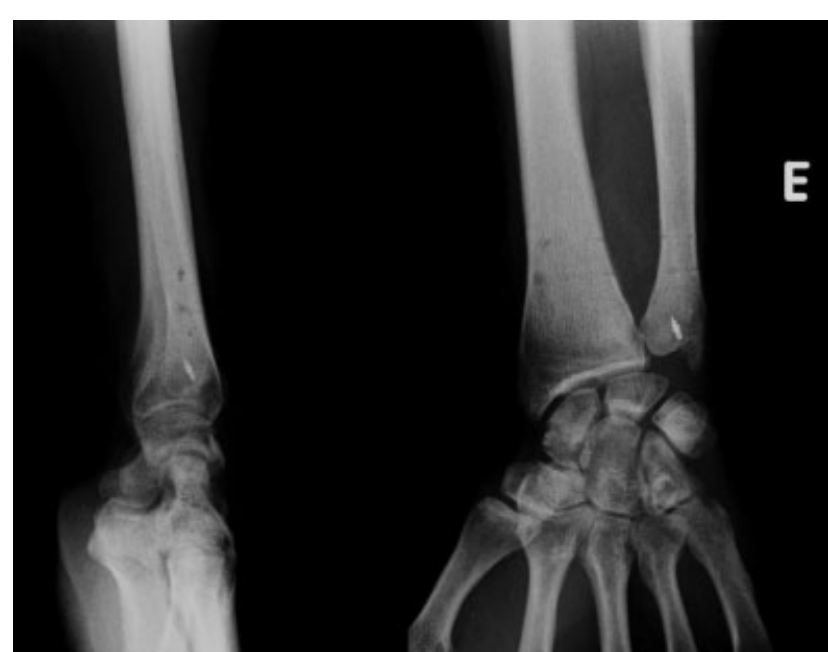

Fig. 7 Final X-ray.

dislocations. Two of these were dorsal dislocations, one was a volar dislocation, and all were treated with closed reduction and pinning.

In our case, the treatment option (open reduction, TFCC reattachment and dorsal plicature) is similar to the treatment chosen by other authors. ${ }^{4,5}$ After the first two weeks, we chose to allow extension and flexion of the wrist and elbow while maintaining the pronation-supination blocked with Kirschner wires. This was a risky decision, because it increased the risk of Kirschner-wire breakage. It was allowed because we believed the patient to be able to understand the risk and not to try to force forbidden movements. During this time he came to the hospital weekly.

The range of motion obtained, namely the supination, was below what we expected. This might be attributed to a plicature of the dorsal capsule that was too tense, or to the fact that the patient was only allowed to try making supination 12 weeks after the operation. This period of immobilization was superior to that chosen by other authors, and we believe it was excessive. A better clinical result might have been achieved had supination been allowed after six or seven weeks under the care of a therapist, and that is what we would now recommend in similar cases.

The patient was involved in a work compensation situation that may have also influenced the clinical outcome. However, he was pleased with the final result, did not desire further surgery, and was especially pleased for being able to resume his previous occupation.

The literature seems to indicate that while diagnosed in the acute setting, a reduction of an isolated DRUJ dislocation should always be attempted. It is, however, important to make sure that complete reduction is obtained, and that it is stable. Pinning the joint is safer than a simple cast in maintaining reduction. If a closed reduction is not possible, an open reduction should be performed, as well as a reattachment of the TFCC.

In a chronic setting, closed reduction is less likely to be possible, and open reduction and stabilization will probably be necessary in most cases.

\section{Conflicts of Interests}

The authors have no conflicts of interests to declare.

\section{References}

1 Distal Radioulnar Joint Instability. In: Green DP, Wolfe SW. Green's operative hand surgery. Philadelphia: Elsevier/Churchill Livingstone; 2011:523

2 Szabo RM. Distal radioulnar joint instability. J Bone Joint Surg Am 2006;88(04):884-894

3 Garcia-Elias M, Smith DE, Llusá M. Surgical approach to the triangular fibrocartilage complex. Tech Hand Up Extrem Surg 2003;7(04):134-140

4 Garrigues GE, Aldridge JM III. Acute irreducible distal radioulnar joint dislocation. A case report. J Bone Joint Surg Am 2007;89(07): 1594-1597

5 Ellanti P, Grieve PP. Acute irreducible isolated anterior distal radioulnar joint dislocation. JHand Surg Eur Vol 2012;37(01): 72-75

6 Rijal L, Sagar G, Ansari T, Joshi A, Joshi KN. Isolated volar dislocation of distal radioulnar joint: rarely occurring, commonly missed. Eur Orthop Traumatol 2012;3(02):151-154

7 Acar E. Surgical treatment of isolated acute dislocation of the distal radioulnar joint without fracture: Case reports of dorsal and volar dislocations. Hand Microsurg 2017;6:154-160 